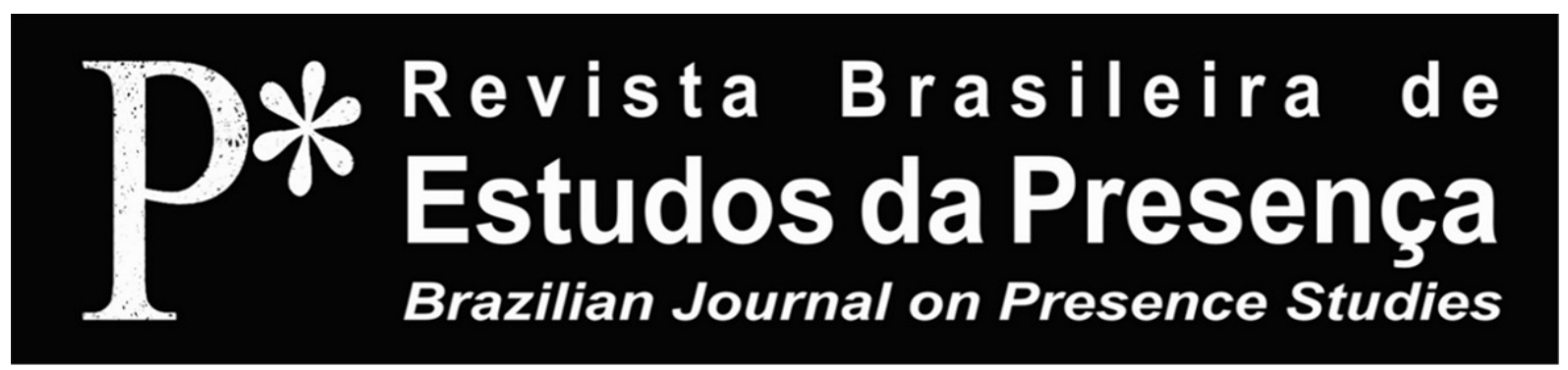

E-ISSN 2237-2660

\title{
Comparing Stage Presence and Virtual Reality Presence
}

\author{
Sebastian Xavier Samur \\ University of Toronto - Toronto, Canada
}

\begin{abstract}
Comparing Stage Presence and Virtual Reality Presence - Reflecting on the impending release of new Head Mounted Display virtual reality (VR) technologies, the article examines definitions and techniques for digital presence, and compares them with research into stage presence. It opens with an outline of definitions of digital presence, comparing them with Cormac Power's fictional, auratic, and literal modes of presence in performance. The article then looks at techniques used in VR and on stage to achieve presence. Finally, performance examples that use virtual reality technologies are presented. The article concludes that even if the technology falls short, discourse on digital presence is useful in providing insights into presence on stage.
\end{abstract}

Keywords: Theatre. Performance. Digital Performance. Presence. Virtual Reality.

RÉSUMÉ - Une Comparaison entre Présence Scénique et Présence en Réalité Virtuelle - Réagissant au lancement de nouveaux visiocasques de réalité virtuelle (RV), l'article examine des définitions et des techniques de présence numérique, les comparant à des recherches sur la présence scénique. Le texte s'ouvre avec un survol de définitions de présence numérique, les comparant avec les modes de présence scénique proposés par Cormac Power (fictif, auratique et littéral). Ensuite, le texte examine les techniques utilisées pour susciter une sensation de présence dans la réalité virtuelle et sur scène. Enfin, le texte conclut que, même si la technologie ne répond pas aux attentes, le discours autour de la présence numérique promeut un nouveau regard sur la présence scénique.

Mots-clés: Théâtre. Performance. Performance Numérique. Présence. Réalité Virtuelle.

RESUMO - Uma Comparação entre Presença Cênica e Presença na Realidade Virtual - Ao refletir sobre o iminente lançamento de novas tecnologias de realidade virtual, como capacetes, o artigo examina definiçóes e técnicas para a presença digital e as compara com a pesquisa em presença no palco. Inicia com definiçóes de presença digital, comparando-as com as modalidades de presença em performance de Power - ficcional, aurática e literal. A seguir, aborda as técnicas utilizadas em RV e no palco para alcançar a presença. $\mathrm{O}$ artigo conclui que, mesmo que a tecnologia náo alcance seu objetivo, o discurso sobre presença digital consegue oferecer insights sobre presença no palco.

Palavras-chave: Teatro. Performance. Performance Digital. Presença. Realidade Virtual. 
With the advent of the Oculus Rift, HTC Vive and other head-mounted display (HMD) virtual reality (VR) technologies, discourse around presence in digital environments is developing quite rapidly. How do attempts to define and understand this phenomenon compare with existing research into presence on stage? Interest in both on-stage and VR presence stems from a desire for immediacy - being in the here and now. Both also involve a suspension of disbelief - a wilful denial of the artificial conventions of a performance or VR creation - on the part of the spectator or user. In comparing the two notions of presence, this article hopes to better understand their similarities and differences as VR technology gradually makes its way on stages. Examining presence in the digital realm will also provide insights into stage (analog?) presence through a new perspective.

As a point of reference, stage presence will follow the definitions outlined by Cormac Power in Presence in Play (2008). In his book, Power outlines three modes of presence on stage - the fictional, auratic, and literal. Fictional presence refers to the extent to which the spectator feels present in relation to the fictional setting or characters of a piece (such as Hamlet). Auratic presence refers to the extent the spectator feels a heightened presence in the actor. This refers to the type of work engaged in by theatre practitioners such as Jerzy Grotowski and Eugenio Barba, which seeks to enhance the actor's presence or aura in the eyes of the spectator. And literal presence refers the spectator's acknowledgement of the theatrical framework. This last mode is often central to performance studies, where the spectator may be described as a witness to a live event. The audience's awareness of both the performer and themselves is heightened, not through the story of a piece or techniques worked on by the performer, but instead by a specific context that is devised by the performer. This is well illustrated when considering durational performances by artists such as Marina Abramović or Chris Burden, where the audience becomes aware of the gradual transformation of both their own and the performer's bodies. In many cases, all three of these modes may be simultaneously at play. Of particular interest in this paper, however, are the techniques and strategies that artists or technicians employ to affect the spectator or user and heighten their sense of presence. 


\section{Evolving Definitions of Digital Presence}

Discussions around presence in virtual environments have been ongoing since the first technologies emerged in the early 1980s. Telepresence was originally used by Marvin Minsky while discussing technologies that extended the body remotely via robotic limbs (1980). The term continued to be used, but the simplified presence also began to be employed to encompass other technological experiences that did not necessarily involve remote tasks. Presence is now used to describe experiences with technologies ranging from remotely activated robots and machines to social media, video games and virtual reality. Each technology allows one to inhabit a virtual environment in some way. Presence with technologies that involve remote activity is measured by the user's ability to complete a task as if they were immediately at hand. With online messaging through chat rooms or programs like Skype, which virtually extend the body's language, sound, and appearance, presence is measured by the degree to which coherent social integration is possible. BeamPro robots (mobile computer screens - think Skype on wheels), which further add the ability to travel remotely, add a heightened potential for remote embodiment beyond the visual and aural. Such technologies are based on virtually transporting one's self for the purposes of everyday communication. They correspond closely to Power's notion of literal presence, as they aim to allow users to feel as though they are actually in a different location. With online worlds, such as Second Life or World of Warcraft, users congregate through customized avatars. In these cases, where one is living vicariously, the sense of presence becomes dependent on the engagement with the artificial world and the investment one makes in the character. Such forms of technology centre on what Power defined as fictional presence, where users lose themselves in the storyline of a piece. Lastly, VR HMD technologies, as well as Augmented Reality technologies (AR) - technologies that alter real environments with computer-generated elements (such as seeing a hologram on stage) - promise new levels of immersion by seamlessly combining the real and the virtual, engaging presence variously, depending on if their function is task-based, social, game-based, or otherwise. Unlike most technologies that involve isolated facets of presence - such as extending the human voice or body - presence with VR HMDs and in augmented reality often 
engages most of the body's faculties, and thus has the potential to make the user escape reality to a greater degree. It is with these last types of technology that one might potentially experience Power's auratic form of presence - a heightened sense of being on the part of a user as they interact with virtual elements or other users in a virtual environment.

As with defining presence in theatre and performance studies, definitions of presence in the virtual realm have evolved considerably. An early definition outlined by Thomas Sheridan (1992) distinguished between telepresence (feeling present at a remote location via technologies) and virtual presence (feeling present within a virtual environment). Sheridan (1992) argues, however, that the degree of presence in both cases is dependent on three factors: sensory information received, the ability to control the sensory environment (such as shifting one's viewpoint), and the ability to manipulate the physical environment. The senses - particularly visual and audio data that help situate the user - are central in this early definition, in addition to personal agency. It also contains similar elements as a definition later posited by David Schloerb (1995). Schloerb, who uses the term telepresence to encompass elements of teleoperation and virtual presence, distinguishes between objective and subjective telepresence. The former is possible if a user is able to complete a specific task, while the latter is defined by the user's perception of his or her virtual environment. Again, one sees the distinction between the user's sensory information and their ability to successfully modify the virtual environment. The ability to modify one's environment will generally correspond with Power's idea of literally being present, while audio and visual stimuli will certainly play a role in all three modes, whether fictional, auratic, or literal. Stage presence, however, usually involves a social aspect that is absent from Sheridan and Schloerb's definitions of virtual presence. Beyond visual and audio cues, audience members of a performance can intuit through reciprocal apprehension (what Edmund Husserl (1960, p. 112) referred to as intersubjective pairing in his phenomenology) whether a performer is living in the moment or whether they are no longer engaged in the performance.

Some technology scholars have included a social dimension in their definitions of virtual presence. Carrie Heeter (1992) divides 
presence into three facets: personal, social, and environmental. Personal presence refers to awareness of one's own body/self in a virtual space; social presence to one's awareness of others (human or computer-generated) in the virtual space; and environmental presence to awareness of elements in the virtual space itself (Heeter, 1992). The social dimension is also included in a widely cited definition by Matthew Lombard and Theresa Ditton (1997) that includes six elements: 1) social richness: the extent to which a virtual social interaction resembles one in reality, which may be characterized by feelings of warmth or intimacy; 2) realism: the extent to which the virtual environment resembles reality; 3) transportation: the feeling of either being transported elsewhere, having objects or another location brought to the user, or two users feeling transported to a different space; 4) immersion: the extent to which one feels psychologically and perceptually immersed in the environment; 5) social actor within medium: defined by the user's ability to control or interact with his or her environment; 6) medium as social actor: the sense that the medium (whether computer or digital environment) is interacting with the user. As with previous definitions, audio and visual sense cues are important for Lombard and Ditton, as they affect one's experience of immersion and realism. However, the other elements are relatively distinct from those proposed by Sheridan and Schloerb. The social richness and transportation elements are certainly affected by the senses, but also by psychological factors. Being a social actor or feeling as though the medium is a social actor refers to the interactive relationship with the technology. This relates to user agency, but is based more on the exchange that takes place between user and technology, rather than being strictly user-centric or taskbased. Such social elements would certainly be central in all three of Power's modes of presence, and highlights the fact that presence in performance (and in computer simulations where the user is not alone) involves a co-dependent relationship between two parties, each of which is aware (or seemingly aware) of the other. Although it is difficult to specifically characterize the social relationship necessary for presence in these cases - Lombard and Ditton link it to a sense of intimacy, as well as to interaction - it is clear that simply generating audio and visual content will not lead to a credible sense of presence. The audience must become psychologically engaged with the performer or the computer-generated content. 
The social and psychological dimensions of VR have become of particular interest to scholars working in the medical sciences and psychology, who have begun using the technology regularly in their practices. In these cases, computer programs aim to foster various forms of Power's literal presence for the user, as they emulate reallife situations. Surgery can increasingly be undertaken remotely, and medical training may sometimes employ VR technologies. Robert Riener and Matthias Harder's book Virtual Reality in Medicine (2012) contains a useful overview of the technology in the field. In addition to treating physical conditions, medical practitioners must also develop soft (social) skills in order to foster confidence in patient care. VR technology in medicine must thus account for the fact that a real human is being treated, in order to avoid alienating the patient. In psychology, researchers have also begun testing out VR to help patients with phobias, such as acrophobia or arachnophobia (Hodges et al, 1994; Peperkorn; Mühlberger, 2013). Virtual exposure therapy has the potential to gradually help patients overcome their fears through virtual experiences in a safe environment. In testing out these capabilities, presence is still defined by elements such as the user's senses - believing in the audio and visual computer-generated content - and ability to complete tasks, but other factors, such as fear and anxiety, are also taken into account. For the user of an arachnophobia simulation, a sense of presence not only arises from believing in the computer graphics representing a spider crawling over one's hand, but is heightened by the consequent emotional response. Positive correlations between anxiety and the sensation of presence have been discussed in several studies (Bouchard; St-Jacques; Robillard; Renaud, 2008; Peperkorn; Mühlberger, 2013; Peperkorn; Diemer; and Mühlberger, 2015). It is not clear, however, whether a user's pre-existing anxiety increases his or her likelihood of feeling present, or if anxiety-inducing VR content encourages the sensation of presence. As this relationship is better understood, it will likely influence the content produced, both for uses in psychology and elsewhere. In the following section, techniques for playing with the link between anxiety and presence in both virtual reality and live performance will be discussed.

Finally, a recent definition of presence was provided during a 2014 talk on VR technology as part of Steam's Dev Days. The 
chief scientist for the Oculus Rift, Michael Abrash, outlined his views on presence. He defined VR presence as "the sense that you are really someplace" and distinguished it from immersion, where one feels "surrounded by the image of the virtual world" rather than in it (Abrash, 2014, p. 16). This distinction recalls the previous arachnophobia simulation example, and the difference between simply seeing the computer-generated spider, and believing becoming psychologically affected - by it. For Abrash, once a certain degree of realism is achieved in virtual reality, the user shifts from immersion to presence. Abrash also noted that presence varied from person to person, and outlined the technical requirements he believed were needed to establish presence. These included the following elements: 1) A wide field of view (at least 80 degrees; promotes immersion); 2) Adequate resolution (at least 1080p); 3) Low pixel persistence (the length of time a pixel remains lit; it should be less than 3ms); 4) A high enough refresh rate (at least 95Hz); 5) Global display (illuminating all pixels simultaneously); 6) Optics (only one or at most two lenses per eye); 7) Optical calibration (calibrating for the human eye is one the greatest challenges as getting it wrong often induces motion sickness); 8) Head tracking (should support $\mathrm{x}, \mathrm{y}, \mathrm{z}$ position to at least $1 \mathrm{~mm}$ and orientation to at least a quarter degree); 9) Low latency (at most $20 \mathrm{~ms}$ ). This definition is useful in outlining the technical requirements for establishing presence with current HMD technology; however, like Sheridan (1992) and Schloerb (1995), it focuses primarily on informing the user's senses (and solely the visual senses), which aid in resituating the user's literal present setting. It does not take into account the social, psychological, or interactive dimensions that will be central to VR programs that go beyond a single user in a computer-generated environment. This absence is striking as it presents a relatively simple formula for achieving presence. It is perhaps sufficient for many of the Vive's current demos, such as WEVR's TheBlu: Encounter (2015), in which the user walks around on a sunken ship. Underwater, he or she is surrounded by schools of fish, manta rays, and a large blue whale that swims past. The user is alone, and limited to a 4 X4 meter space, and is engaged with primarily visual (but also audio) content. Similarly, in the Vive's most recent demo, Everest (2015), developed by Sólfar Studios and RVX, a solo user climbs over a crevice on their way up 


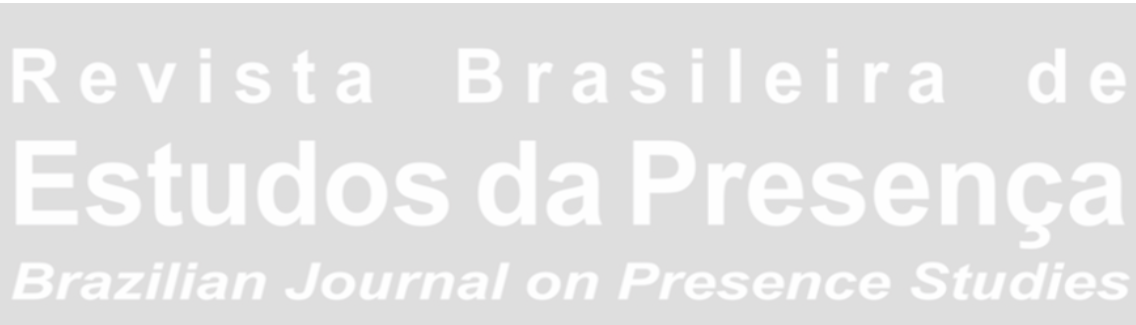

Mount Everest. The user must make their way over a couple ladders by walking and using handheld controllers. Those who have tried the demo have reported not only belief in the visual environment, but also felt as if they were physically climbing, cold, and afraid when looking down. Both demo programs attempt to transport the user from their literal present - wearing the HMD in a small cubic space - to the literal present of a vast natural environment. The realism of the computer content in the demo takes the user beyond the immersion of simply being surrounded by a series of images (as one might set up using Google Maps, for instance), reaching a point where the user is psychologically affected. It is noteworthy that primarily visual content can so profoundly affect one's sense of literal presence. As programs become increasingly complex, however, additional contributing aspects will likely need to be considered. The multiplicity of factors to account for and the ambitious aims of VR technology - to simulate reality (or a fictional reality) - will likely necessitate an interdisciplinary approach.

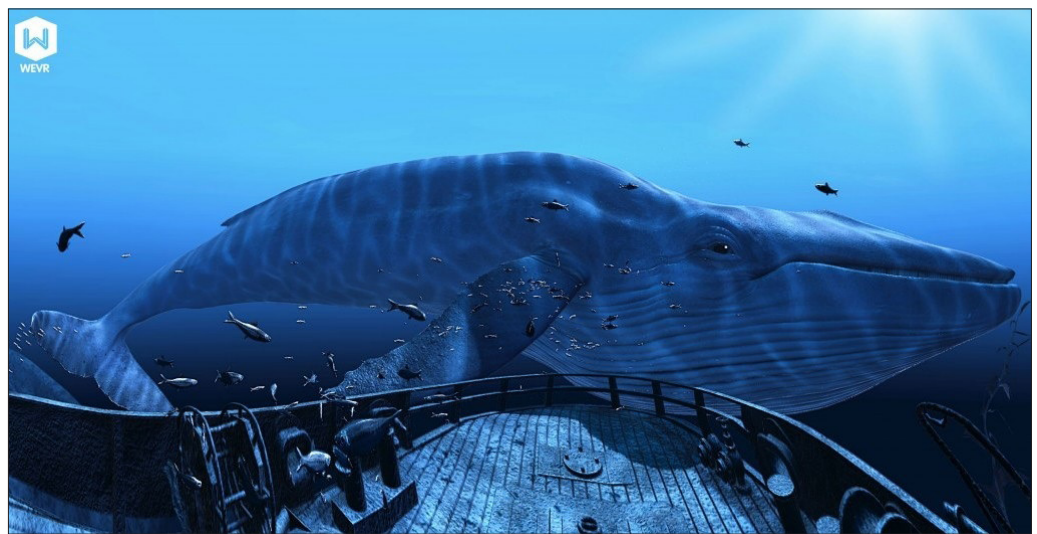

Image 1 - Screenshot from theBlu: The Encounter (2015); Artist: WEVR.

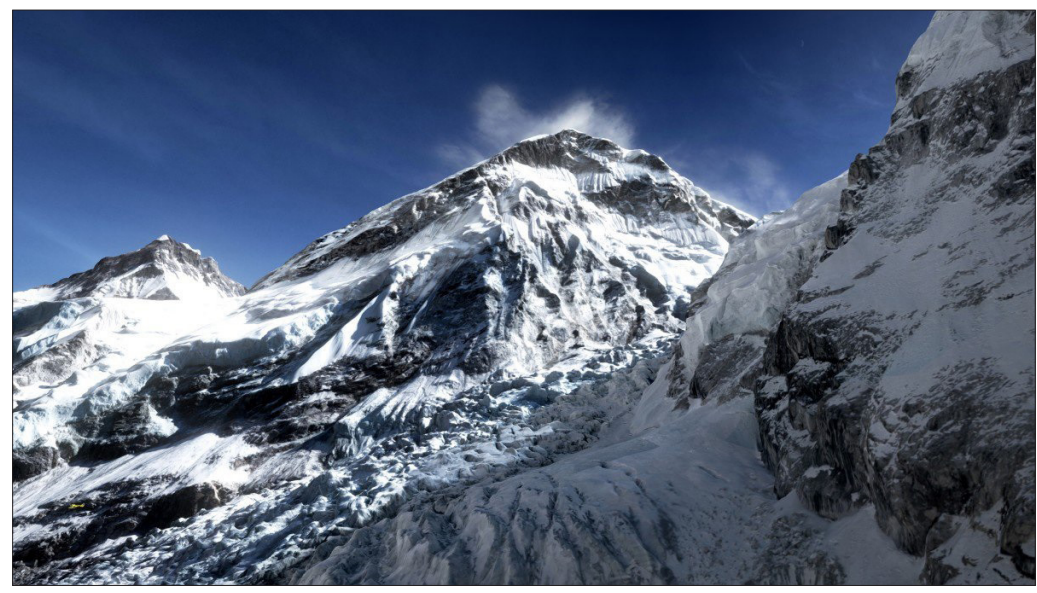

Image 2 - Screenshot from Everest (2016); Artists: Sólfar Studios and RVX.

Sebastian Xavier Samur - Comparing Stage Presence and Virtual Reality Presence Rev. Bras. Estud. Presença, Porto Alegre, v. 6, n. 2, p. 242-264, May/Aug. 2016. Available at: <http://www.seer.ufrgs.br/presenca > 


\section{Achieving Presence in VR and On Stage}

While the means and techniques for enhancing presence in VR and on stage vary significantly, they both ultimately aim to provide an immediate experience for the user or spectator - the sense that what is being experienced is real (or at least believable) and occurring in that moment, perhaps even for the first time. Lombard and Ditton's examination of presence provides a good starting point for comparison, as one finds analogous elements in work on theatre presence. The element of realism, for example, equates with believability on stage or illusion. Just as a VR user must believe in the reality of the people and objects in a virtual environment, so must an audience believe the characters portrayed by the actor. VR aims to make the user forget outside reality, as they become immersed in the virtual environment. In some cases, these experiences can even lead to real world accidents, as users react physically to objects or people projected on a screen. Such an engrossing illusion has at times been similarly attempted on stage. The naturalist movement, for instance, aimed to create a total illusion for the audience by incorporating real elements, such as detailed sets or the use of real scents. Current site-specific performances play with a similar idea, incorporating real-world sites and objects to provide additional levels of detail.

Many site-specific performances can also relate to the transportation element of Lombard and Ditton's definition. In numerous site-specific performances, the audience is physically displaced to a particular location, the act of which helps transport the audience into the fictional world of the production. Where a performance takes place at a historical site, the performance may also transport the audience into the imagined literal past of that location. In the majority of performance productions, however, spectators are stationary, as are VR users, and it is technical elements, whether scenographic on stage or computer-generated in VR, that transport them to another world. When considering the concept of transportation in the setting (time and place) of a performance, it is easy to situate Power's fictional and literal modes of presence, but the auratic mode can also be characterized by transportation. On stage, the actor's technique may transport the spectator. In The Presence of the Actor (1972), Joseph Chaikin, writing on the actor's presence, states "It's a quality that makes you feel as though you're standing 
right next to the actor, no matter where you're sitting in the theater" (p. 20). Transportation, then, is a common goal in establishing presence both on stage and in VR.

Continuing with the social and interactive elements of presence in Lombard and Ditton's definition, these elements are important to note because they remind us that presence is not necessarily about an individual experience, but often about the exchange between users or between user and computer-generated elements. On stage, this relationship takes place between performers and audience and in some interactive productions between audience members. Though work on developing stage presence is often done individually by the actor (or in building complicité between two or more actors), performers are ultimately working to improve their immediate relation to the audience. Patrice Pavis highlights this relation in his Dictionary of Theatre (1998): "The $I$ can only be created in relation to a you, to whom one lends one's own ego through identification" (p. 286). As previously seen, Abrash's recent talk does not foreground the social aspect of presence in VR. The user's interactive relationship in VR is thus in need of further development. It will be intriguing to see if particular techniques or behaviours emerge to heighten a VR user's presence in the eyes of another, the way actors may train to develop their auratic presence. Or perhaps, as seen in a preliminary study by Kober and Neuper (2012), one's feeling of presence is more dependent on personality factors. The authors found that those who had higher absorption tendencies (the ability to give one's full attention) were more likely to experience feelings of presence with VR technology. This would certainly corroborate Abrash's statement that VR presence varies from person to person.

On stage, for practitioners that investigate the auratic mode of presence, the actor's body is the primary site of work, involving both physical and mental exercises. Stanislavski's work on concentration and memory, later exercises in method acting, or Barba's intercultural research and ideas on pre-expressivity exemplify the kinds of techniques actors engage to become present on stage. Grotowski also worked on the actor's body and experimented extensively with different audience-performer relationships, the way many companies today presenting interactive theatre do. Punchdrunk's Sleep No More (2011) demonstrates this kind of performance, which depends 
greatly on the audience's choice and active participation. The audience follows a number of characters from Macbeth throughout a five-floor building, and must choose who they follow (or if they explore the building independently). Interest in such performances is often motivated by the promise of a unique or authentic experience, purportedly rooted in the present, rather than a reiteration of a previous performance. Certainly the conventional proscenium arch and long performance runs encourages the audience to think they are seeing a repeat event or another piece of theatre. By simply giving the audience agency of their literal location, this preconception is mitigated. VR technology can similarly assign a more active role to the spectator. Rather than simply watching events pass by, as so many users have before them, they may have to make choices and interact with their environment to advance in a program. Open world environments, found in Second Life and in video game series such as Grand Theft Auto and The Elder Scrolls, create the promise of an experience that is unique to them, reinforcing the feeling of presence as the narratives the users create are tailored to their choices. Interactivity can heighten an audience's sense of fictional presence as they realize what they are currently experiencing is the result of past choices made.

Returning to Pavis' (1998, p. 286) dictionary definition of presence, he suggests that "[...] rather than the actor's presence, we could speak of the continual present of the stage". As seen in the discussion of realism, the audience's sense of presence can arise from the space, whether real or virtual. There is thus much to be gained by controlling the audience's perception of their environment - by shaping the literal mode elements of presence. A study by Steinicke, Bruder, Hinrichs, and Steed (2010) suggests that providing a transitional environment from reality to VR could improve a user's sense of presence. Moreover, in VR, where HMDs are employed, the user's perception is significantly limited to the screen and headphones, allowing programmers a considerable degree of control over audience experience. In theatre, Wagner's Festspielhaus exemplifies a similar desire for control of the audience's perception, as the physical design of the space narrowed the audience's focus to the stage, the theatre was darkened (as most theatres do today) to further control the perspective, and the orchestra was hidden to avoid breaking the 
illusion on stage. Limiting the audience's perspective, often through sensory deprivation or limitation, is a useful means for enhancing feelings of presence, which may explain in part the increased use of HMDs for VR, rather than CAVE (Cave Automatic Virtual Environment) technology, which surrounds the user with screens on three to six sides. Many current demo programs available for the Oculus Rift and HTC Vive take the audience's limitations into account and are designed to take advantage of them. Jaywalkers Interactive's Blue Marble (2013) and Simon Phillips' Solar System Explorer (2014), for example, let users float through space, making use of the user's stationary position and darkened field of view. In Blue Marble, the user is limited to simply gazing out over planet Earth as music plays and the video slowly tours the planet for a few minutes. In Solar System Explorer, the experience is similar, but the user has control over a ship, and can visit the different planets in the solar system. Outer space is ideal as a setting for exploration because its vastness and the relative slowness of space travel suit well the slower movements that work best with current HMD technology, limiting possible nausea and a user's subsequent disengagement from the game.

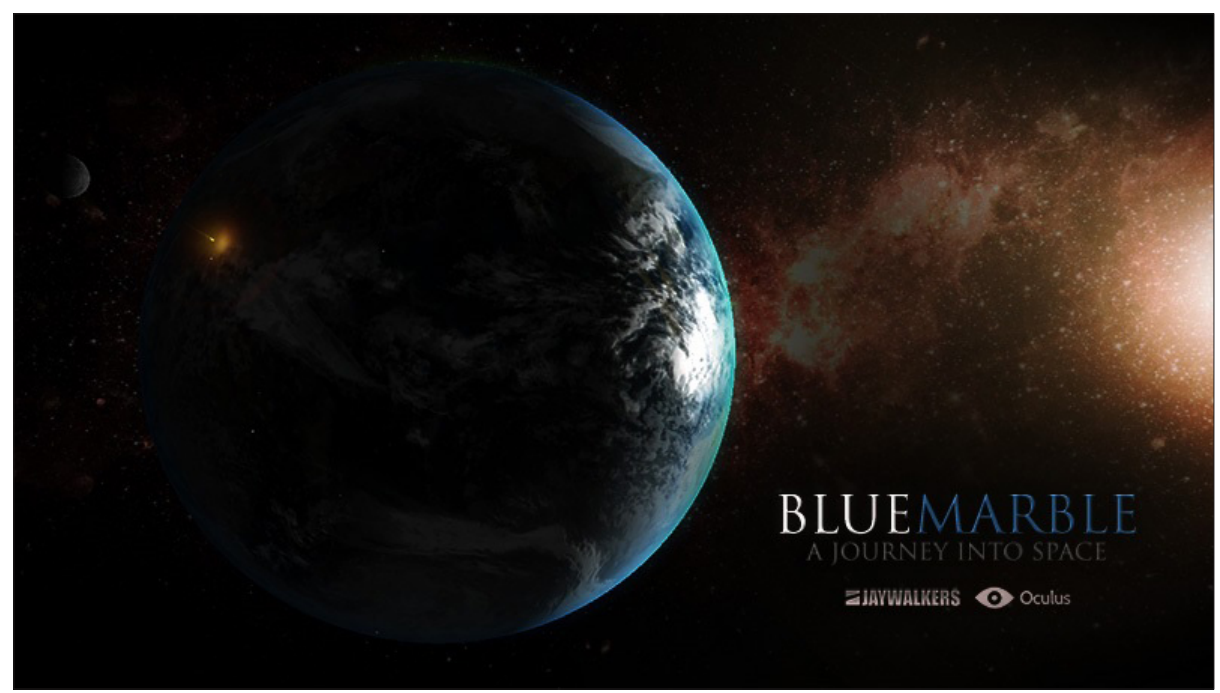

Image 3 - Screenshot from Blue Marble (2013); Artist: Jaywalkers Interactive.

Taking similar advantage of a user's limited perspective, horror games such as White Door Games' Dreadhalls (2013) or Enno Gottschalk's Lost in the Rift (2013) use darkened lighting and multidirectional sound to disorient or surprise the user. In Dreadhalls, the user must navigate through a randomly generated dungeon maze. Lit by torchlight, the user makes their way through narrow corridors, 
peeking around corners, and slowly opening chests and doors. Fear in the game arises out of the claustrophobic setting and the ever-present (though seldom occurring) possibility of something jumping out at the user. The sound of wind, doors closing and echoing, as well as intimate whispers contrast with louder, sometimes jarring music, to create suspense and anxiety in the user. Similar claustrophobic elements are found in Lost in the Rift. Beginning outside in a dark forest, full of branches that obstruct vision, the user, armed only with a flashlight, gradually makes his or her way into a narrow cave with corridors. Again, light sounds of rain, and later of a young girl whispering contrast with louder, eerie music to build suspense. In both Dreadhalls and Lost in the Rift, limited lighting is used to control the user's experience. Sound, played at different volumes and between left and right headphones, disorients the user, building their anxiety, and heightening their awareness of surroundings. Little action is actually needed to build fear in the user - only the possibility of danger from somewhere in the environment. The games establish both literal and fictional modes of presence, and it is notable that sound is so central to the experiences. Audio, however, was completely absent from Abrash's breakdown of elements necessary for presence in VR. It focused solely on visual elements, yet, as in film, audio may be central in smoothing out transitions between different visual environments. Studies by Poeschl, Wall, and Doering (2013) and Nordahl (2005) have confirmed a heightened sense of presence when sound is strategically used, whether spatially, or in connection with the user's motion. A consistent audio stream may help in preserving one sense of presence. In performance, audio plays a similar role in preserving the illusion on stage, as music aids in scenic transitions. Loud, atmospheric, or multidirectional sound can be used to engage or surprise audiences. Similarly, contrast in lighting effects can be used for disorientation. For example, in Theatre No99 No51 My Wife Got Angry (2014), a multimedia performance about a man recalling past events, the lights are briefly shut off and turned on again, revealing a half-dozen characters from the protagonists' memory on stage. Daniel MacIvor used a similar effect in his solo performance about life in suburbia, Cul-De-Sac (2005), the lights flashing brightly, temporarily blinding the audience, while the actor takes his first position sitting in a chair. Neither show would be 
classified as a horror piece, but the technique befits theatre's need to keep audiences guessing. Despite their simplicity, such effects are effective in creating a sense of presence, as they disorient the audience and force them to immediately assess their surroundings.

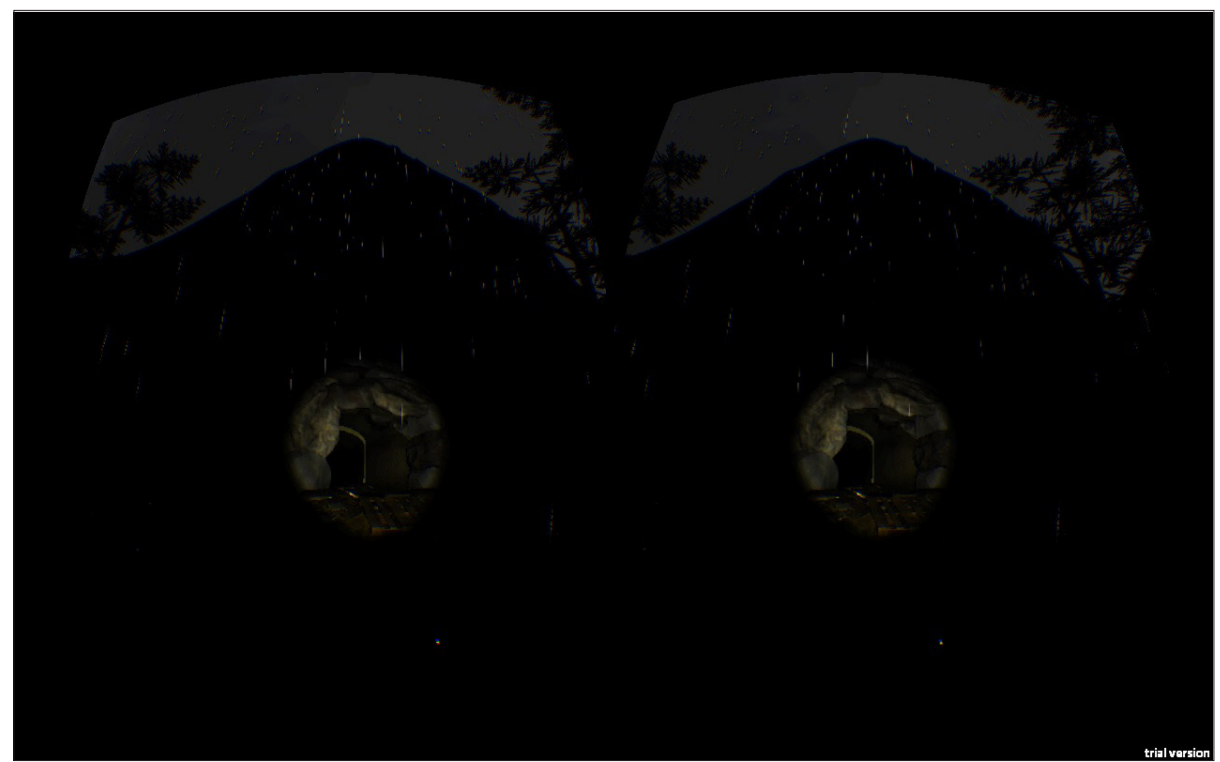

Image 4 - Screenshot Lost in the Rift (2013); Artist: Enno Gottschalk.

Exploration of the relationship between fear or anxiety and presence in VR is one that has only somewhat been explored in theatre and performance. As previously mentioned, various studies in VR have shown a positive correlation between fear or anxiety and feelings of presence. This is perhaps unsurprising as when people are fearful, their primal instincts begin to engage. Awareness of present surroundings increases, and they may even become irrational, increasing the likelihood that they will believe in the reality of their environment. The closest correlates in theatre and performance are those that place the spectator in an unfamiliar situation. Sleep No More, for example, places the audience in a situation where their freedom to explore also makes them vulnerable to unknown surprises. Smaller, more intimate, pieces also engage a feeling of presence in audiences through their vulnerability. Hush Productions' Mobile Thriller (2004), for example, takes an audience of three for an evening performance in the back of a car. Anxiety is heightened by the fact that the audience cannot easily escape the moving vehicle, the way one might in a traditional theatre presentation. In another example, Jennifer Doyle opens her book Hold it Against Me (2013) with her experience of Adrian Howells' Held (2007). In the one-to- 
one performance, Howells sits and chats with an audience member, they later hold hands, and eventually they lie on a bed together. Doyle writes of her anxiety being late for her appointment (which she eventually misses), and suggests she subconsciously sabotaged the meeting out of fear for what might happen during the encounter. In addition to enhancing VR presence, then, fear and anxiety may also enhance the audience's experience of presence on stage and in performance. Practitioners wishing to engage presence in this way must then design their productions to place the audience in unfamiliar, disorienting, or intimate situations that will heighten their anxiety level, and, perhaps in turn, their sense of presence.

\section{VR Encounters with the Stage}

Though not comprehensive, Steve Dixon's article $A$ History of Virtual Reality in Performance (2006) provides a useful outline of VR's short history in theatre and performance up until 2006. A number of examples using HMD technology are included. In Toni Dove and Michael Mackenzie's The Archeology of a Mother Tongue (1993), for example, HMDs are used to explore digital imagery, supplemented by a data glove (which transmits data from the user's hand into the virtual environment). In Char Davies' Osmose (1994-95), the user wears a HMD as well as a datasuit (like the data glove, but transmitting information on the body's position) to explore a naturebased environment. It is notable that even in these earlier productions, additional technologies - the data glove and datasuit - supplement the HMD. The Oculus Rift and the HTC Vive can similarly be enhanced by auxiliary tracking technologies, in the form of their constellation and lighthouse systems, respectively. External cameras are used to track the user within a limited space, and reportedly enhance the user's experience of presence, as they can participate more actively in programs such as a cooking demo designed for the HTC Vive. At the 2016 Consumer Electronics Show, HTC also unveiled a new Vive Pre model that incorporates an outfacing camera on the HMD unit. It allows programmers to digitize the user's external environment, so the user can accurately identify real objects around them, such as tables and chairs, within the virtual landscape. It presents a potential cross-over point between VR and AR, further smoothing the boundaries between real and virtual worlds. As 
discussed in the previous section, however, HMD technology's inherent limitations can also be dramaturgically beneficial. Sublime and Ridiculous' In My Shoes (2014) uses the constraints of HMD technology to explore the disorientation that may arise from brain injuries. The user wears Vuzix 920 video glasses and iPod earphones, and is taken on a narrative journey that recreates one of the company members' experiences of waking up disoriented after a seizure. The group takes advantage of the user's limited vision and hearing by incorporating elements of touch and smell to encourage a total sense of presence. Limiting the audience's perspective in this case is used to promote understanding and empathy, engaging, to various degrees, all three of Power's modes of presence: the literal, by transporting the user to a different, virtual location; the fictional, by the user's interest in the story; and the auratic, by heightening their bodily sensations. Of course, passive spectatorship may be enough for many VR experiences. The Adelaide Symphony Orchestra's The Classics Unwrapped Virtual Reality Concert Series (2015), designed in partnership with Jumpgate VR, invites audience members to wear HMDs and be transported on stage with the rest of the orchestra, facing the conductor, Guy Noble. The HMDs allow the audience to engage more immediately with the performance's literal present, as they can more easily identify the musical contributions of each instrument. The technology, in this case, is used as a new means of engaging with orchestral works and promoting musical education, which do not necessarily require a high level of interactivity.

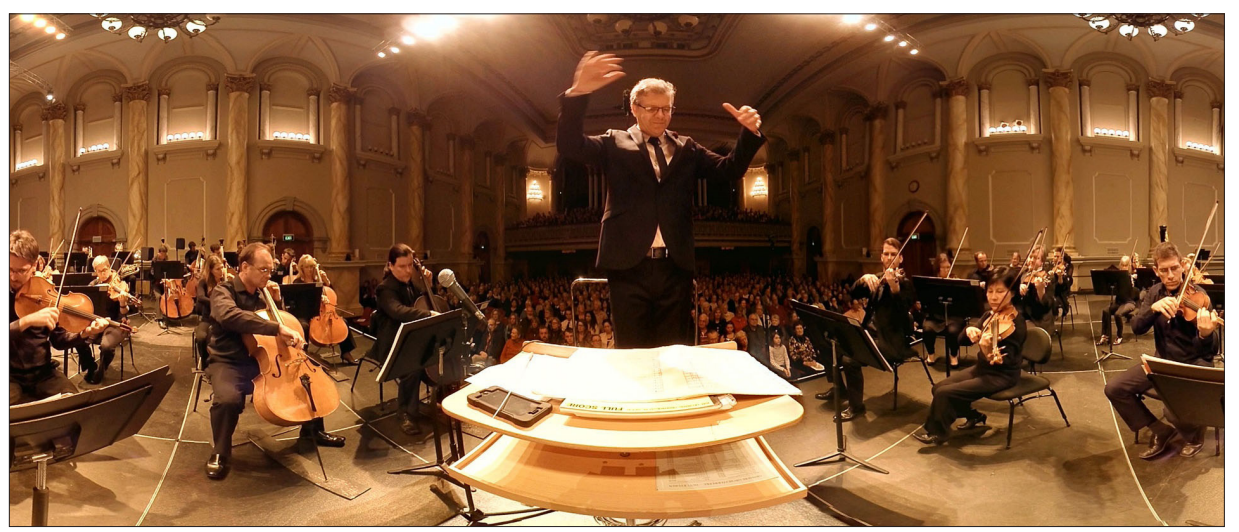

Image 5 - Screenshot from The Classics Unwrapped Virtual Reality Concert Series (2015); Artists: The Adelaide Symphony Orchestra and Jumpgate VR.

CAVE technology presents another medium for performance practitioners to explore virtual presence possibilities. In his article, 
Dixon writes extensively on Blast Theory's Desert Rain (1999), which, similar to CAVE technology, encompasses users within a projected environment. The installation for six users invites participants on a search mission set in the Gulf War. It engages both the literal and fictional modes of presence, as users experience a narrative reality of historical experience. More recently, Nick Kaye and Gabriella Giannachi experimented with CAVE technologies as part of their Performing Presence research project. Through a number of different VR scenarios, the spectator is placed in dialogue with a digitally projected virtual counterpart. According to Kaye and Giannachi (2011, p. 91):

[...] rather than deploy CAVE's simulations toward a displacement of the participant's attention from their 'real' circumstances and contexts - from the physical cube and the VR lab, from the 'real' individuals who facilitate the experiment - and toward an ostensibly unified illusion of a virtual world, these scenarios emphasize exchanges, dialogues, and thematic reversals between the simulated and the real, provoking an awareness of the layers and doubling within which CAVE functions even as its virtual worlds unfold.

Rather than attempting to seamlessly blur the line between reality and the virtual, Kaye and Giannachi seek to emphasize the divide between the two and the multiple layers of presence that emerge in contemplating it. It exemplifies a potential for VR technology to engage the auratic mode of presence, as a user becomes aware of the virtual possibilities of their body. Unfortunately, such VR CAVE experiments are relatively rare in performance, as the technology requires a dedicated space for only one or two users.

The above performances notwithstanding, virtual scenography is currently the most predominant way in which VR technologies are presently used on stage, and it is worth contemplating to what extent it can be considered VR. As a CAVE environment expands from a small cubicle to a full-stage box or backdrop, how does one's feeling of presence shift? CAVE environments are generally designed for a single user, as seen in Performing Presence. However, a similar, and much larger, interactive box environment was designed for Cadenza+'s Mr. and Mrs. Dream (2014) using Kinect sensors. In this production, two dancers perform amid a series of interactive projections, including imagery of shape-shifting furniture, crowds 
of people, text, elements from space, and more abstract objects. It is arguable that the performers will still experience a sensation of virtual presence as they perform, though perhaps it is diminished by the lack of intimacy with the space. This is to the benefit of the spectators who are able to share the performers' experience of the virtual environment. In this case, multiple modes of presence are engaged. The projected imagery works to make both the audience and dancers feel as though the performers are part of the literal and fictional present of the virtual landscape - that, as part of the narrative, they are actually on a moving conveyor belt, jumping on a trampoline, or moving within a field of asteroids, for example. At the same time, the auratic mode may be engaged, as the combined human-virtual performance space may heighten or extend the actors' presence for the audience. By contrast, in a production such as AddIng Machlne: A Muslcal (2013) by the University of Kansas' Institute for the Exploration of Virtual Realities (i.e.VR - Dixon also comments on their earlier productions) it may primarily be the audience that experiences a sensation of digital presence between performers and projections, as they are best positioned to take in the combined effect. The scenographic projections, including a bedroom, a ticking clock, a courtroom, and a jail, among others, are all situated upstage of the performers, rather than around them. They serve primarily to situate the fictional present of the stage action. A similar example is found in The Magic Flute (2012), a co-production between Germany's Komische Opera Berlin and the UK's 1927. In this performance, actors play in front of highly detailed fairytale imagery, such as a spiderweb, a dark forest, or town rooftops. The digital backdrops are so large, however, that it is unlikely the performers experience a sense of immersion with the digital background. Only the audience is truly able to perceive the performers enmeshed in the digital environment, which contributes primarily to the fictional present of the performance.

Finally, Dixon also examines the use of VR technology in reproducing stages. In particular, he points to Warwick University's 3D Visualisation Unit, which recreated stages from antiquity, such as the Theatre of Pompeii or the Theatre of Dionysus to be viewed on a screen. The early work is useful for theatre history scholars as it transports users back to the literal present of the historical setting. The user's awareness of their literal presence is doubled in this case, as 
they are aware of their actual present, viewing the computer screen, and simultaneously immerse themselves in the literal (debatably fictional) present of the simulation. Unfortunately the simulation does not incorporate performances on the stage; however, recent work in Japan, has attempted to do so, recreating historical Noh and Kabuki plays on VR stages. Kohei Furukawa et al (2006) recreated a VR Noh stage, complete with performance, while Tomoki Nakaya et al (2010) created a virtual Kabuki stage and performance as part of The Virtual Kyoto Project. Motion capture was used in both cases, and the performances were viewable on computer screens. The user's sense of presence in these examples is limited by the use of computer screens, rather than HMD or CAVE technology. Nevertheless, introducing an actual performance allows one to experience the fictional present of the plays, which in turn heightens one's experience of being in the literal present of the virtual historical settings. Oculus VR's demo VR Cinema (2013) similarly engages the fictional and literal modes of presence. The program recreates the simple experience of visiting a movie theatre. The audience member can look and move around the space to choose a seat. He or she can then watch a selected movie, which appears to the user as if it is projected onto a large screen. The idea is rather strange - to use a VR HMD to go to the movies - but it is one of the more popular demos released for the Oculus Rift to date due to the level of presence it engages in the user. The audience feels literally at the movie theatre, and this in turn contributes to their engagement with the fictional present of the movie on screen. When one considers the increasing use of live-streamed theatre (including Kabuki) performances into movie theatres, it becomes clear that all the pieces necessary to create either live contemporary or recreated historical performances have already been developed. It is only a question of time, then, before they are combined to allow for VR theatre spectatorship. 


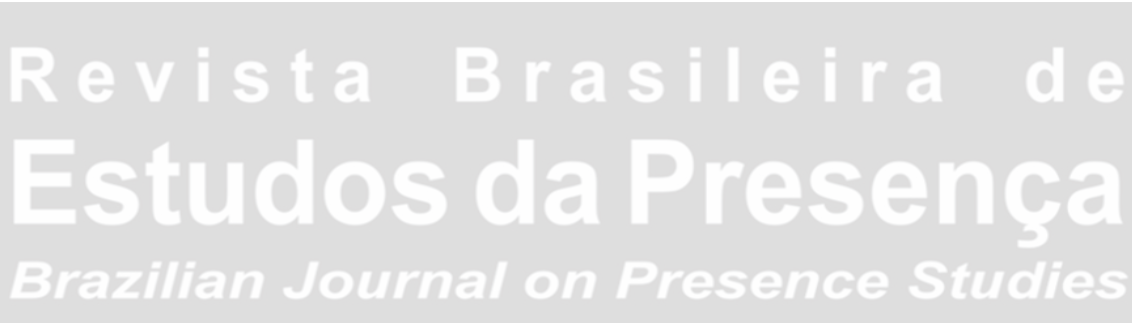

E-ISSN 2237-2660

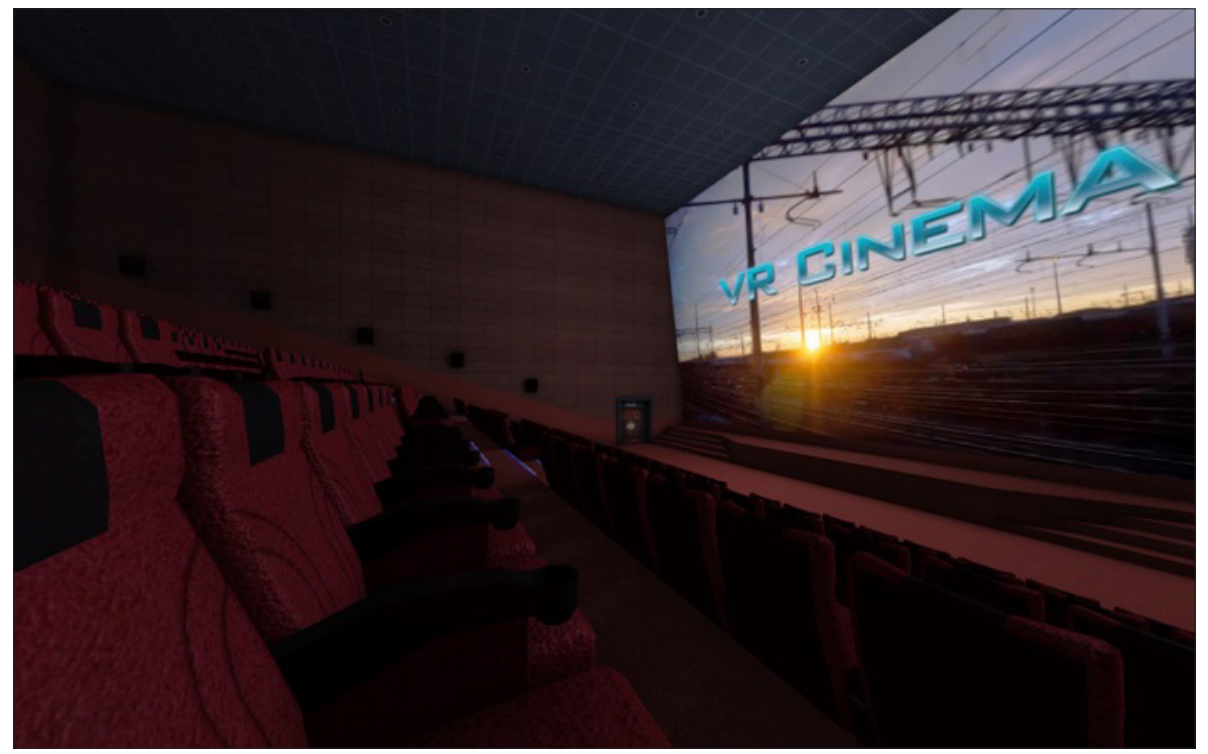

Image 6 - Screenshot from VR Cinema (2013); Artist: Oculus VR.

\section{Conclusion}

At the conclusion of his article, Dixon notes that VR continues to fall short of its formidable ambitions, and a decade later the situation is arguably the same. However, recent aggressive investments in VR HMDs, including the Oculus Rift, HTC Vive, Samsung Gear, and Playstation's Project Morpheus, have significantly improved the technology's performance specifications, as well as created widespread interest that goes far beyond the uptake of VR in the 1990s. In 2016, consumers will be able select from a number of VR technologies, which will likely further software and hardware development. They will discover how, in various ways, the technology can transport them to the literal present of different locales, engage them in the narrative storytelling of fictional worlds, and potentially heighten their auratic presence in the eyes of other users. In the very near term, users will decide whether or not the upgraded VR HMDs do indeed provide a significant leap in promoting the sensation of digital presence, and what possibilities the experience might proffer. Even if the new technology fails, however, the discourse that is emerging provides useful insights into many other fields, including presence in theatre and performance. As seen with Power's three modes of presence and presence definitions posited by technology scholars, there are common elements in both VR and performance that enrich understanding of presence in both realms and also highlight new 
potential areas for exploration, such as the link between anxiety, disorientation, and feelings of presence. It is also noteworthy that heightening one mode or facet of presence can in turn stimulate others - engaging in the fictional present of a performance on a virtual historic stage, for example, heightening one's sense of being in another literal location. As discussion and creation continues, further theoretical and practical applications will be uncovered, which will further our understanding of what it means to be present. 


\section{References}

ABRASH, Michael. What VR Could, Should, and Most Certainly Will Be Within Two Years. Presentation. Notes. 2014. Available at: <https://www.media.steampowered.com/ apps/abrashblog/Abrash\%20Dev\%20Days\%202014.pdf2014>. Accessed: 15, Sept., 2015.

BOUCHARD, Stéphane; ST-JACQUES, Julie; ROBILLARD, Geneviève; RENAUD, Patrice. Anxiety Increases the Feeling of Presence in Virtual Reality. Presence: Teleoperators and Virtual Environments. Cambridge, MIT, v. 17, n. 4, p. 376-391, Aug 2008.

CHAIKIN, Joseph. The Presence of the Actor. New York: Atheneum, 1972.

DIXON, Steve. A History of Virtual Reality in Performance. International Journal of Performance Arts and Digital Media, Online, Taylor and Francis - Routledge Journals, v. 2, n. 1, p. 23-54, 2006 (Print), Jan 2014 (Online).

DOYLE, Jennifer. Hold it Against Me. Durham: Duke University, 2013.

FURUKAWA, Kohei; WOONG, Choi; HACHIMURA, Kozaburo; ARAKI, Kaori. CG Restoration of a Historical Noh Stage and Its Use for Edutainment. In: ZHA, Hongbin; PAN, Zhigeng; THWAITES, Hal; ADDISON, Alonzo; FORTE Maurizio (Ed.). Interactive Technologies and Sociotechnical Systems. Berlin: Springer, 2006. P. 358-367.

HEETER, Carrie. Being There: The Subjective Experience of Presence. Presence: Teleoperators and Virtual Environments, Cambridge, MIT, v. 1, n. 2, p. 262-271, Spring 1992.

HODGES, Larry et al. Presence as the Defining Factor in VR Application. Technical Report. Atlanta: Georgia Institute of Technology, 1994.

HUSSERL, Edmund. Cartesian Meditations: An Introduction to Phenomenology. Translation: Dorion Cairns. The Hague: Martinus Nijhoff Publishers, 1960.

KAYE, Nick; GIANNACHI, Gabriella. Acts of Presence: Performance, Mediation, Virtual Reality. TDR: The Drama Review, Cambridge, MIT, v. 55, n. 4, p. 88-95, Winter 2011. KOBER, Silvia; NEUPER, Christa. Personality and Presence in Virtual Reality: Does Their Relationship Depend on the Used Presence Measure? International Journal of HumanComputer Interaction, Online, Taylor and Francis, v. 29, n. 1, p. 13-25, Mar. 2012.

LOMBARD, Matthew; DITTON, Theresa. At the Heart of it All: The Concept of Presence. Journal of Computer-Mediated Communication, Online, International Communication Association, v. 3, n. 2, n. p. Sep 1997.

MINSKY, Marvin. Telepresence. OMNI Magazine, New York, Jun. 1980.

NAKAYA, Tomoki et al. Virtual Kyoto Project: Digital Diorama of the Past, Present, and Future of the Historical City of Kyoto. In: ISHIDA, Toru (Ed.). Culture and Computing: Computing and Communication for Crosscultural Interaction. Berlin: Springer, 2010. P. 173-187.

NORDAHL, Rolf. Self-Induced Footsteps Sounds in Virtual Reality: Latency, Recognition, Quality, and Presence. In: THE $8^{\text {TH }}$ ANNUAL INTERNATIONAL WORKSHOP ON PRESENCE: PRESENCE 2005. Conference Paper, International Society for Presence Research, 2005. P. 353-355. 
PAVIS, Patrice. Dictionary of the Theatre: terms, concepts, and analysis. Toronto: University of Toronto, 1998.

PEPERKORN, Henrik; MÜHLBERGER, Andreas. The Impact of Different Perceptual Cues on Fear and Presence in Virtual Reality. In: WIEDERHOLD, Brenda; RIVA, Giuseppe (Ed.). Annual Review of Cybertherapy and Telemedicine. Online: IOS Press, 2013.

PEPERKORN, Henrik; DIEMER, Julia; MÜHLBERGER, Andreas. Temporal Dynamics in the Relation Between Presence and Fear in Virtual Reality. Computers in Human Behavior, Amsterdam, Elsevier, v. 48, p. 542-547, Jul 2015.

POESCHL, Sandra; WALL, Konstantin; DOERING, Nicola. Integration of Spatial Sound in Immersive Virtual Environments: An Experimental Study on Effects of Spatial Sound on Presence. In: VIRTUAL REALITY (VR), 2013 IEEE. Conference Paper, Mar 2013. P. 129-130.

POWER, Cormac. Presence in Play. Amsterdam: Rodopi, 2008.

RIENER, Robert; HARDER, Matthias. Virtual Reality in Medicine. London: Springer Science and Business Media, 2012.

SCHLOERB, David. A Quantitative Measure of Telepresence. Presence: Teleoperators and Virtual Environments. Cambridge, MIT, v. 4, n. 1, p. 64-80, Feb 1995.

SHERIDAN, Thomas. Musings on Telepresence and Virtual Presence. Presence: Teleoperators and Virtual Environments. Cambridge, MIT, v. 1, n. 1, p. 120-126, Winter 1992.

STEINICKE, Frank; BRUDER, Gerd; HINRICHS, Klaus; STEED, Anthony. Gradual Transitions and Their Effects on Presence and Distance Estimation. Computers and Graphics, Amsterdam, Elsevier, v. 34, n. 1, p. 26-33, Feb 2010.

Sebastian Samur is a doctoral student at the University of Toronto. He received his Master of Arts from the Université du Québec à Montréal. Interested in actor training, he trained with SITI Company, Roy Hart Theatre, Dairakudakan, and the Grotowski Workcentre. He is also interested in intermedial theatre, and has written on the use of androids in medical simulation in Canadian Theatre Review. E-mail: sebastian.samur@gmail.com

This unpublished text, proofread by Ananyr Porto Fajardo, is also published in Portuguese in this issue.

Received in September 29, 2015 Accepted in February 5 ${ }^{\text {th }}, 2016$ 